\title{
ALTERNATIVE THEORIES OF WAGE DETERMINATION AND UNEMPLOYMENT IN LDC'S: THE LABOR TURNOVER MODEL *
}

\author{
Joseph E. Stiglitz
}

I. Introduction, 194. - II. The model, 196. - III. The market equilibrium, 205. - IV. Optimal allocation of labor and determination of urban wage level, 207. - V. Wage subsidies, 214.-VI. Wages and shadow price of labor in the public sector, 218. - VII. Urban income taxes, 220. - VIII. Concluding comments and summary, 222.-Appendix: "nominal" and "expected" urban wages and the unemployment rate, 223.

\section{INTRODUCTION}

The problem of unemployment and underemployment in LDC's has long been a central concern of development economics. More recently, the discussion has focused on unemployment and underemployment in the urban sector. The common diagnosis of the source of urban unemployment, particularly in economies such as those in East Africa where there does not seem to be "surplus labor" in the agricultural sector, is that there is a large wage differential between the urban and rural sectors that encourages migration into the urban sector. And, finally, there seems to be a consensus that the remedies for this - if it is impossible in fact to lower the urban wage to the level in the rural sector - are (a) a wage subsidy to encourage private employers to hire more laborers (use more laborintensive techniques) and (b) the use of a shadow price of labor for projects in the government sector, which is lower than the market wage in the urban sector.

Although economists have advised governments all over the world to undertake these measures, they have based these policy prescriptions on partial equilibrium models that have not traced out the full implications of these policies; in particular, they have failed to take into account (a) the determination of the rate or level of unemployment in the economy and (b) the determination of wages in the urban sector. The possible implications of these failures may easily be seen. If the number of people in the urban sector is fixed,

* This paper was written while the author was a research fellow at the Institute for Development Studies, University of Nairobi (1969-1971), under a grant from the Rockefeller Foundation. The author is indebted to his colleagues at the IDS for many helpful discussions; in particular, he would like to thank G. E. Johnson and L. Smith. Financial support was also provided by the Ford Foundation and the National Science Foundation. 
then hiring one person from the urban unemployed has a zero social cost, and the unemployment rate will be reduced. If the unemployment rate in the urban sector is unchanged, at $U$, hiring one more person will lead to approximately $U$ more unemployed people, so $(1+U)$ people have joined the urban unemployed. What the social cost is then depends on what they were doing before: if they were unemployed in the agricultural sector, then of course the social cost is still zero. But if they were receiving the agricultural wage and this were equal to their marginal product, then there is a significant social cost in excess of the rural wage. ${ }^{1}$ In between, there is the possibility that the number unemployed in the urban sector is constant, so that hiring one individual from the unemployment pool results in an in-migration to the urban sector of one person. If he were employed in the agricultural sector, the opportunity cost would be just the rural marginal product of a laborer. Evidently, those who advocate using something like the rural wage as the shadow price of labor in the urban sector are making this assumption, but on no basis do they justify this assumption.

Similarly, one has to have a theory of the determination of the urban wage to know whether a wage subsidy will be "shifted." Evidently, most of the advocates of wage subsidies believe not only that the urban wage is rigid downward, but also that it is rigid upward; yet even noncompetitive bargaining theories would suggest that some of the wage subsidy is absorbed by the workers in the form of higher nominal wages. If this is the case, a wage subsidy might exacerbate the unemployment problem by increasing the nominal differential between urban and rural wages.

What is called for then is a simple general equilibrium model of a less developed country, explaining simultaneously the determination of wage differentials, urban unemployment, the allocation of labor between the urban and rural sectors, etc. This is the object of this paper.

We call the model presented here the "labor turnover model" because of the central role that labor turnover plays in it. Turnover costs (hiring and training) are greater in the urban sector than in the rural. The turnover rate is a decreasing function of the wage

1. Others have advocated using a shadow wage in excess of the rural wage because of the distributional implications of alternative employment policies; i.e., since workers consume a large fraction of their income, increasing urban employment will reduce savings. Since the shadow price of savings is in excess of that for consumption, it is optimal to hire workers to a point where their marginal product is somewhere between the urban and rural wage. In this paper we focus solely on the implications of wage and employment policy for the static equilibrium. 
rate in the urban sector relative to the wage rate in the rural sector; therefore it pays each competitive firm in the urban sector to offer more than the rural wage.

Studies in East Africa ${ }^{2}$ have stressed the importance of turnover in determining the structure of the labor market there, and it undoubtedly plays an important role in other areas as well. It should be emphasized, however, that in other economies, other factors may play a dominant role in determining urban wages. We have explored the policy implications of some of the more important of these elsewhere. ${ }^{3}$

In this paper we contrast three equilibria: the competitive market equilibrium; the "second best" optimum where the government cannot control migration directly, but can control urban wages and employment; and the "third best" optimum where the government controls the urban sector only indirectly by using wage subsidies in the private sector and by using shadow prices for public employment that differ from market prices. The "first best" solution, where the government controls migration directly, does not appear to be feasible without the government taking oppressive measures. ${ }^{4}$ The results of the analysis contradict much of the popular folklore on development.

\section{The Model}

\section{A. Wage Policy of the Individual Firm.}

Since the crucial way in which our model differs from earlier models of dual economies is in the determination of the wage rate in the urban sector, we begin our analysis with a discussion of firm behavior in the urban sector. The representative firm produces output $Q_{u}$ by means of a set of production processes that can be described by a production function of the form

2. Walter Elkan, Migrants and Proletarians (Oxford: University Press, 1960); and W. Elkan, "An African Labour Force," East African Studies, No. 7, Kampala, 1955.

3. See in particular the more extended version of this paper, available as Cowles Foundation Discussion Paper No. 335; and "Alternative Theories of Wage Determination and Unemployment in L.D.C.'s: II. The Efficiency-Wage Model," Cowles Foundation Discussion Paper No. 357, 1973.

The fact that labor turnover is important in determining the level of urban wages does not rule out the possibility that institutional factors - e.g., unions - may be important as well.

4. A number of governments have attempted, unsuccessfully, to control migration directly by requiring all residents in urban areas to have work permits or pay taxes. When individuals are found without employment in the urban sector, they are returned to their native villages, but they return shortly to the city. 


$$
Q_{u}=F\left(K_{u}, L_{u}\right)
$$

with

$$
F_{L L}<0,
$$

where $K_{u}$ and $L_{u}$ are the capital and labor employed by the representative urban firm. ${ }^{5}$ All labor is assumed to be homogeneous. ${ }^{6}$

Since our point here is the analysis of equilibrium positions, and not the dynamics by which they are reached, we shall assume that the capital stock is given. ${ }^{7}$ The firm wishes to maximize its profits; to do this, it must minimize its labor costs. Labor costs consist of wage payments plus training and hiring costs. ${ }^{8}$ Included in the latter is the lost output (broken machines, etc.) that inevitably results when a new employee is hired. The training-hiring costs per worker $T$ are assumed for simplicity to be constant. Thus, total training costs are a function of the rate of turnover of employees. The rate of turnover of employees is a function, in turn, of the wage paid by the firm $w_{u}$ in comparison with (a) wages paid by other firms in the urban sector and (b) wages paid in the rural sector $w_{r}$. It is also a function of the rate of unemployment $U$. If $q$ is the quit rate, i.e., the percentage of the labor force quitting at any time,

$$
q=q\left(w_{u} / E w_{u}, w_{u} / w_{r}, U\right),
$$

where $E w_{u}$ is the average wage paid by all firms in the urban sector. ${ }^{9}$ We assume that

$$
q_{i}<0, i=1,2,3 .
$$

5. Throughout, we shall use the subscript $u$ to denote variables pertaining to the urban sector and the subscript $r$ to refer to variables pertaining to the rural sector.

6 . In other words, we focus on the determination of the urban unskilled wage. The determination of wages and unemployment rates among the skilled raises very different issues. See, for instance, G. Fields, "Private and Social Returns to Investment in Education in Kenya," University of Michigan, 1972.

7. For the same reason, it makes no difference to our short-run equilibrium analysis whether $F$ is constant returns to scale.

It should be emphasized that the longer-run implications of the various policies discussed below, e.g., a wage subsidy, may be quite different from the short-run implications. Not only may such policies affect the level of savings (a point that has already received extensive attention in the literature) but also the intersectoral allocation of capital.

8. These are assumed to be specific rather than general training costs.

9. More accurately, the quit rate is a function of the wage paid by this firm and the entire distribution of wages paid by other firms in the urban sector. Since in our model we are assuming all firms in the urban sector are identical, all firms pay the same wage in equilibrium, and so the distribution is the improper distribution at $E w_{u}$. Nonetheless, individual firms may contemplate altering the wage they pay from that of the rest of the sector. (For a more extensive discussion of the theory of labor turnover and the structure of wages, see J. Stiglitz, "Labor Turnover and the Wage Structure," mimeo, 1973 , paper available from the author on request.) We assume in this paper that the only means of affecting the turnover rate is to lower the wage. There are other instruments available, e.g., seniority pay, but these are sufficiently weak to leave a significant amount of turnover to be affected by wage levels. 
(Later, we shall need to impose some further weak restrictions on q.) The average period of employment is increased by (the quit rate is reduced by) an increase in the wage paid by this firm relative to other firms and relative to the rural sector, and by an increase in the unemployment rate.

There are three sources of labor turnover (besides death and old age retirements): individuals quit to take other jobs in the urban sector, individuals quit to return to the rural sector, ${ }^{1}$ and individuals quit to seek other jobs in the urban sector, in the meantime joining the unemployment pool. The three arguments of our labor turnover function take account of these three alternative sources of labor turnover. In addition, the unemployment rate enters in still two further ways:

1. When an individual is hired by a new firm, there is some probability that it will turn out that he is unsuitable for the job (so will be fired) or that he will dislike the job (or the personnel associated with it) and therefore seek to find still another job. The ease with which this is accomplished depends on the unemployment rate.

2. Much has been written in recent years on rural-urban migration. In the African context, there is also an important urbanrural migration. ${ }^{2}$ Individuals leave the urban sector to return to their rural homes. They may subsequently return to the urban sector after a period of work or leisure in the rural districts. The ease with which they can find employment when they return to the urban sector depends on the unemployment rate, and hence the attractiveness of leaving the urban sector for a respite in the rural depends on the unemployment rate. To take the extreme case, if there were no unemployment whenever they grew "tired" of urban sector, they would quit, for they would know that as soon as they wanted an urban job once again, they could acquire one. The unemployment rate acts to discourage this rural-urban-rural remigration.

The firm's total labor costs then are

$$
w_{u} L_{u}+q T L_{u} \equiv w^{*}{ }_{u} L_{u},
$$

where $w^{*}{ }_{u}$ is the total labor cost per employee. For a given $L_{u}$, the firm seeks to minimize the cost per employee; it takes the unem-

1. In other words, we assume that the substitution effect of a higher urban-rural wage differential in discouraging labor turnover is more important than any possible "income effect." If this is not the case, then $q_{2}>0$ (e.g., if individuals come to the urban sector to accumulate a fixed amount of savings). Whether $q_{2} \gtrless 0$ does not affect our qualitative results, as the reader can check for himself.

2. This has been particularly emphasized in the works of Elkan, op. cit. 
ployment rate and the wage rate of other firms as given and chooses $w_{u}$ to minimize $w_{u}+q T$. This yields the first-order condition ${ }^{3}$

$$
1+T\left(\frac{q_{1}}{E w_{u}}+\frac{q_{2}}{w_{r}}\right)=0 .
$$

The marginal savings in turnover costs must be equal to the extra wage costs.

In Figure I we have depicted graphically the firm's choice of a

q

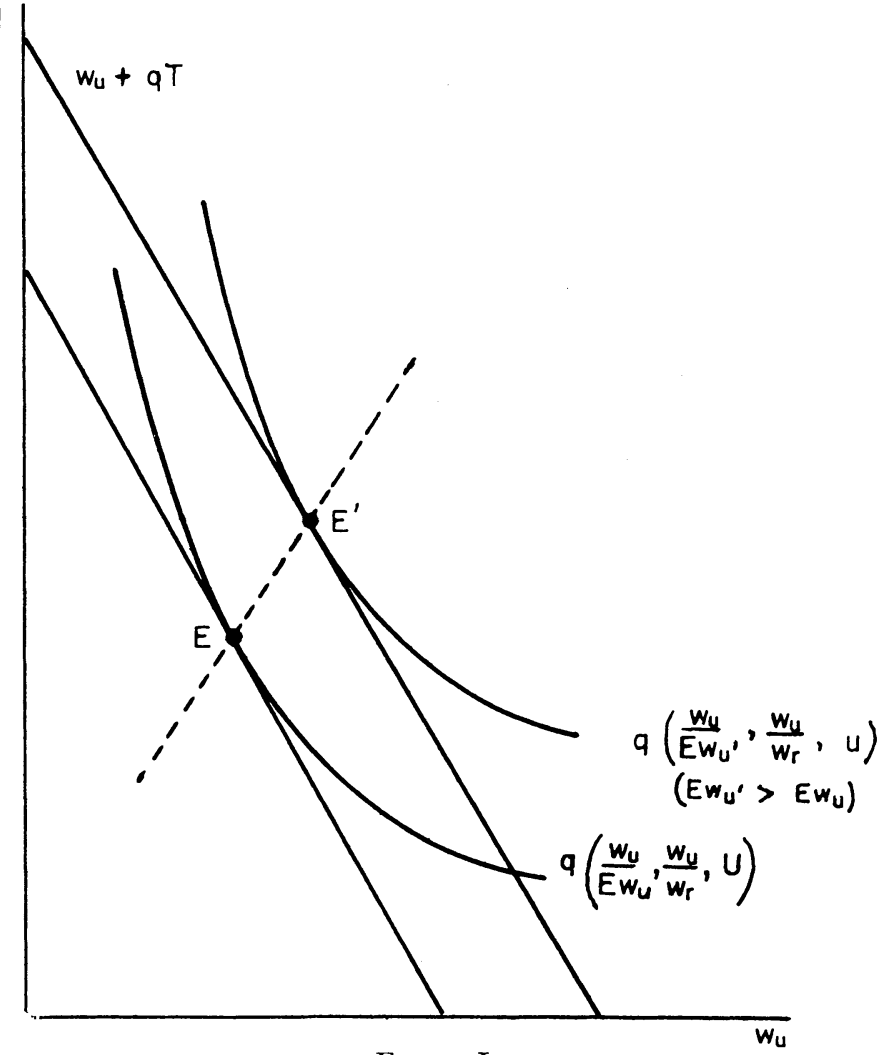

Firm's Choice of Optimal Wage Rate

3 . The second-order condition requires that

$$
\frac{q_{11}}{E w_{u}{ }^{2}}+2 \frac{q_{12}}{E w_{u} w_{r}}+\frac{q_{22}}{w_{r}^{2}}>0 .
$$

The formulation of firm behavior used here is chosen for expositional simplicity. More formally, we should have firms maximizing the present discounted values of net revenues. When firms have fully adjusted their employment to the given capital stock, the wage the firm pays will satisfy (A), but instead of (9) below, we obtain

$\left(9^{\prime}\right) \quad F_{L}=w_{u}+T(q+r)$,

where $r$ is the interest rate. The qualitative results of our analysis are unaffected by this modification. 
wage rate for fixed unemployment rate $U$ and given average wage rate in the urban sector $E w_{u}$. We have plotted two different quitrate functions, corresponding to different $E w_{u}$. The firm chooses a "quit-rate-wage" combination at a point such as $E$, where the quitrate function is tangent to an isolabor cost curve $w_{u}+T q$.

Since we are assuming that all firms are identical, equilibrium in the urban labor market requires that all firms pay the same wage:

$$
w_{u}=E w_{u} \text {. }
$$

Substituting (5) into (4), we can solve for $w_{u}$ as a function of the parameters facing the urban sector $U$ and $w_{r}$ and training costs $T$,

$$
w_{u}=\Omega\left(U, w_{r}, T\right) .
$$

Normally, we would expect anything that increases labor turnover costs to the firm at the old wages (i.e., increased training costs or quit rates) would lead firms to pay higher wages partly to offset

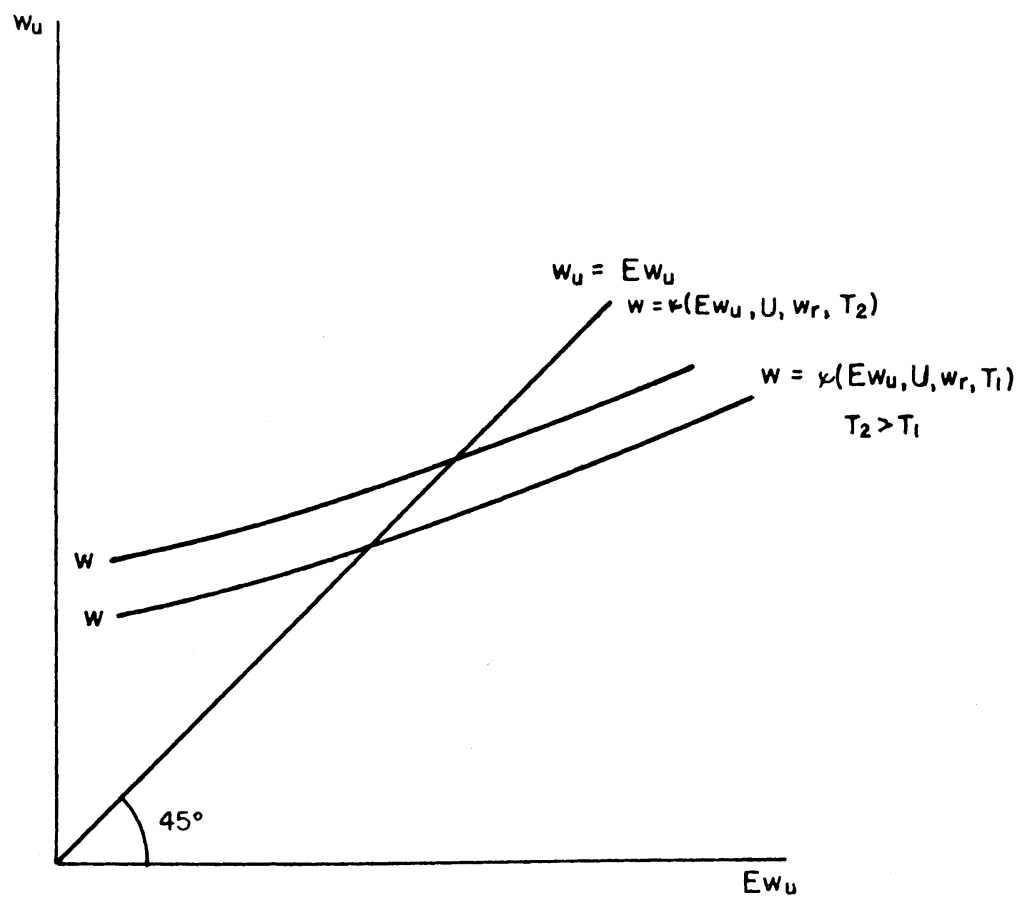

FIGURE II

Determination of Equilibrium Urban Wage and Effect of Increased Training Costs (given $w_{r}$ and $U$ ) 
these increased turnover costs. ${ }^{4}$ Thus, we assume that

$$
\Omega_{T}>0, \Omega_{w_{r}}>0, \Omega_{U}<0,
$$

that is, we impose the following restrictions on our quit-rate function (at the equilibrium) $:^{5}$

$$
\begin{array}{ll}
q_{12}+\frac{w_{u}}{w_{r}} q_{22}-\frac{w_{r}}{w_{u}} q_{1}>0 ; \\
q_{12}+\frac{w_{u}}{w_{r}} q_{22}+ & q_{2}>0 ; \\
q_{13}+\frac{w_{u}}{w_{r}} q_{23} & >0 .
\end{array}
$$

To see diagrammatically what these restrictions entail, observe that an increase in training costs will increase, at each value of $E w_{u}$, the value of $w_{u}$ chosen by the firm. Let $\psi\left(E w_{u} ; w_{r}, U, T\right)$ represent the solution to (4) (i.e., solve (4) as a function of $E w_{u}$, $w_{r}, U$, and $T$ ). If an increase in the wages paid by other firms leads the firm in question to raise its wages, but less than proportionately as depicted in Figure I, then $\psi$ will be upward-sloping, and an increase in training costs will increase the equilibrium wage (the wage at which $w_{u}=E w_{u}$ for the representative firm), as depicted in Figure II. Similarly, an increase in the unemployment rate reduces, at each $E w_{u}$, the $w_{u}$ chosen by the representative firm: the quit-rate function moves "downward" in a reasonably uniform fashion, so firms spend less on direct labor costs (wages) as well as on training. The analysis is similar for a change in $w_{r}$. (See Figure III.)

The model of wage determination we have presented here is essentially one of monopolistic competition in the urban labor market. This can perhaps best be seen in Figure IV. Equilibrium requires $w_{u}=E w_{u}$. Hence, as the urban wage rate changes, the only effect on quit rates is from the increase in urban-rural wage differentials. This

4. That is, both direct labor costs and training costs are "normal" factors.

5. Clearly, (2a) and (2c) imply (2b). The relationship between (2a) through (2d) and (7) follows immediately upon differentiation of (4). (2b) will clearly be satisfied if an increase in the urban-rural wage differential decreases the sensitivity of quit rates to intra-urban wage differentials $\left(q_{12}>0\right)$, and $q$ is convex (so $q_{22}>0$ ). Similarly, (2d) is satisfied if, at higher unemployment rates, quit rates respond less to wage differentials, both within the urban sector and between the urban and rural sectors. (2a) and (2b) imply that

$$
\frac{d \ln \Omega}{d \ln w_{r}}=\left[1+\frac{\frac{q_{1}}{w_{u}{ }^{2}}+\frac{q_{2}}{w_{u} w_{r}}}{\frac{q_{12}}{w_{u} w_{r}}+\frac{q_{22}}{w_{r}{ }^{2}}-\frac{q_{1}}{w_{u}{ }^{2}}}\right]<1 .
$$



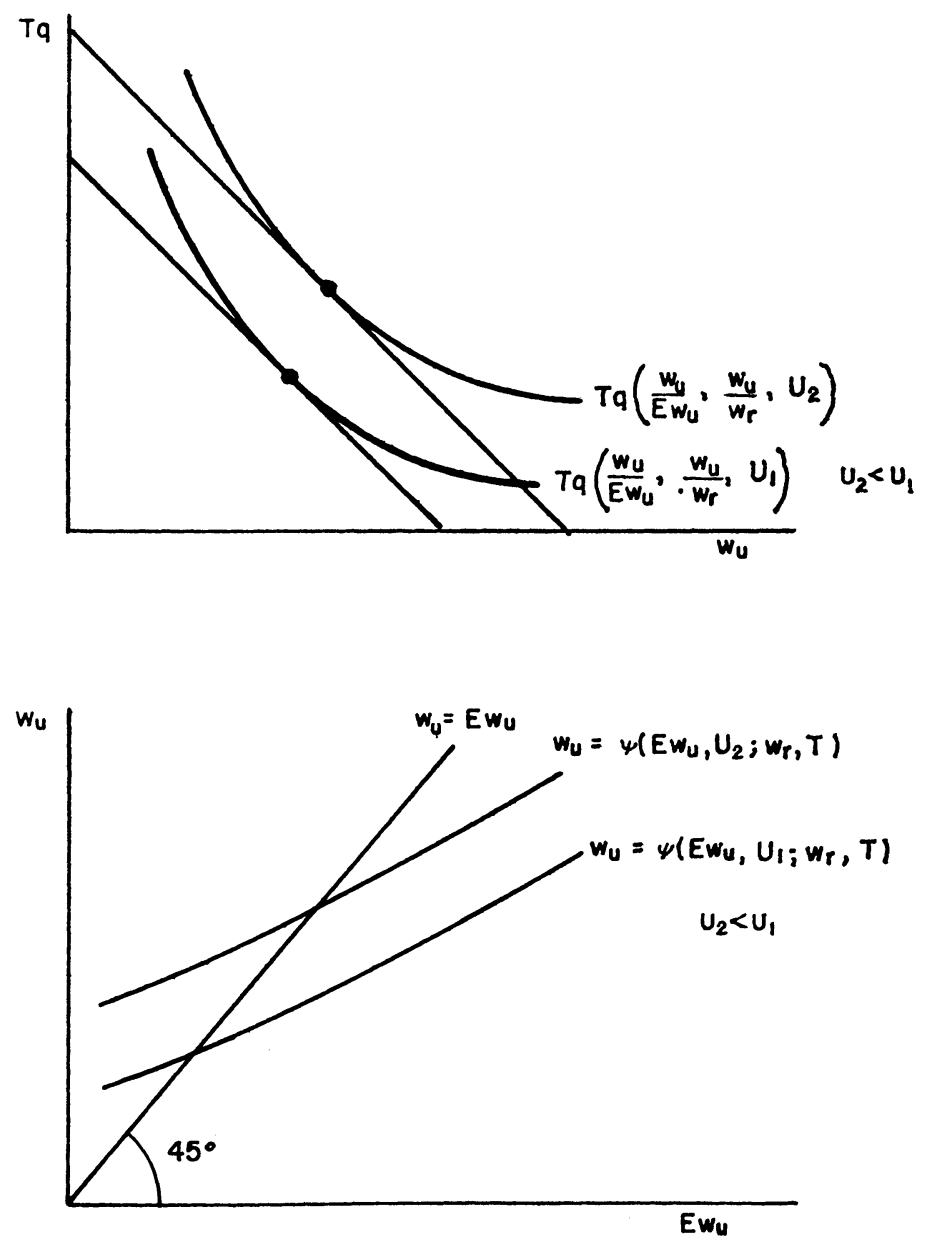

Figure III

Effect of Increased Unemployment Rate on Urban Wage

generates the curve we have labeled $Q Q$. Each firm, on the other hand, believes it can take some competitive advantage of the other firms by raising its wage relative to theirs. The quit function it perceives is steeper than $Q Q$. (It is important to remember that this is still partial equilibrium analysis; throughout, $w_{r}$ and $U$ are assumed given.) The equilibrium is at a point where the $q q$ curve intersects the $Q Q$ curve and has a slope of unity.

B. Urban Employment

The firm chooses its employment level to maximize its profits. 


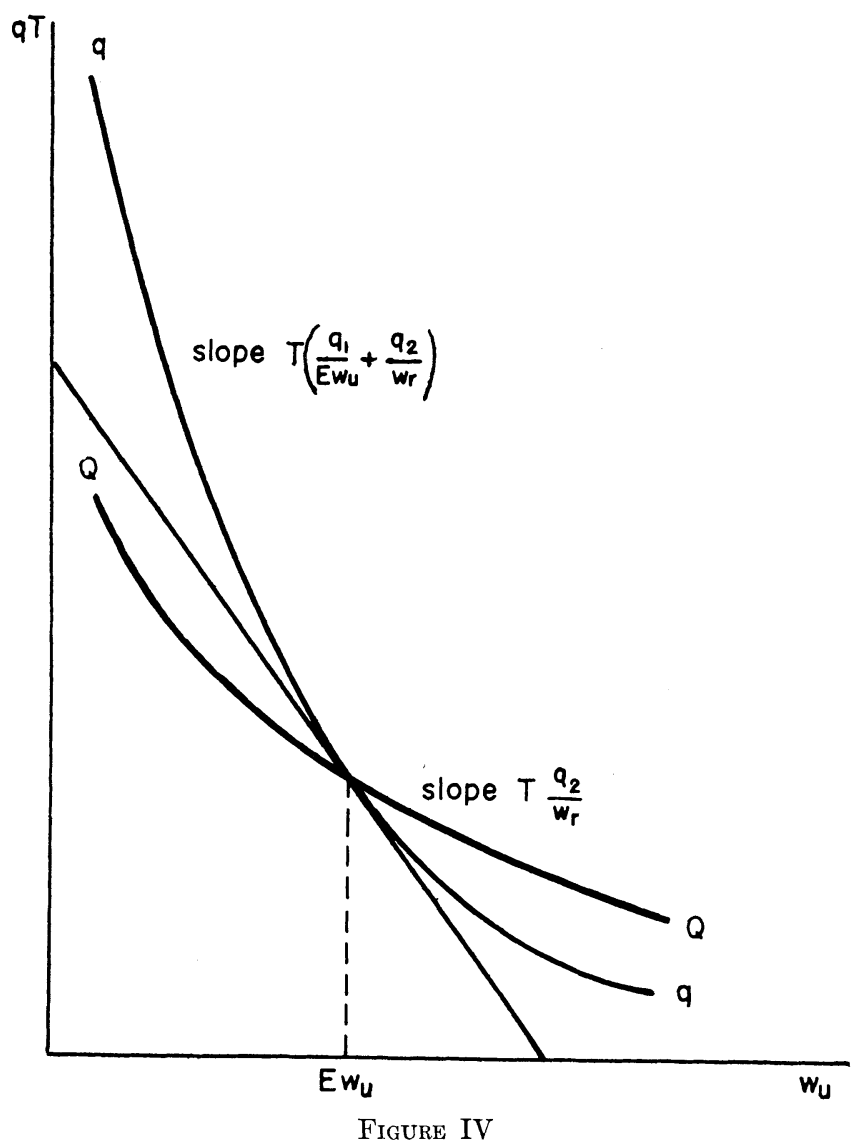

Competitive Choice of Urban Wage Rate (unemployment rate given)

Letting the price of output be unity, then we see that it ${ }^{6}$

$$
\max _{\left\{L_{u}\right\}} F\left(K_{u}, L_{u}\right)-w_{u} L_{u}-T q L_{u}=F-w^{*}{ }_{u} L_{u},
$$

so that

$$
F_{L}=w_{u}+T q=w^{*}{ }_{u}
$$

the marginal productivity of labor is equal to the wage plus training costs. Because $F_{L L}<0$, this can be inverted to solve for the demand for labor by the representative firm, as a function of $w^{*}{ }_{u}$ :

$$
L_{u}=L_{u}{ }^{d}\left(w^{*}{ }_{u} ; K_{u}\right) \text {, }
$$

where $d L_{u} / d w^{*}{ }_{u}=1 / F_{L L}<0$.

6. In principle, the firm is interested in maximizing the discounted cash flow, where presumably the discount rate is equal to the rate of interest. The requisite modifications in (9) are straightforward; their main effect is simply to complicate the algebra. 


\section{Allocation of Labor between Urban and Rural Sector}

If there are large differences in wage rates between the urban and rural sectors, labor will migrate from the rural to the urban sector. More individuals migrate than can find jobs, and it is this that leads to urban unemployment. The unemployment acts to discourage further migration. There will then be a relationship between the magnitude of wage differentials and the equilibrium rate of unemployment. The greater the wage differential, the greater the equilibrium level of unemployment. We write the relationship in the form,

$$
\frac{w_{u}}{w_{r}}=\phi\left(\frac{1}{1-U}\right) \quad \phi^{\prime}>0 .
$$

In certain circumstances, ${ }^{7}$ it can be shown that the "expected urban wage" $w_{u}^{e}$, taking account of the expected duration of unemployment, is

$$
w_{u}^{e}=w_{u}(1-U) .
$$

Hence, in these circumstances if individuals are risk-neutral and migrate to the point where the expected urban wage is equal to the rural wage,

$$
w_{u}^{e}=w_{r}
$$

then (11) takes on the special form of

$$
\frac{w_{u}}{w_{r}}=\frac{1}{1-U} .
$$

For most of our results, (13) is more restrictive than we need. It is both convenient and reasonable, ${ }^{8}$ however, to impose the following restrictions on (11) :

$$
\phi\left(\frac{1}{1-U}\right)(1-U) \geqslant 1
$$

$$
\phi^{\prime} \quad \geqslant 1 \text {. }
$$

The first restriction says that (13) does not underestimate the wage differentials corresponding to any given level of unemployment, and the second restriction says the same thing for changes in wage differentials. ${ }^{9}$

7. See Appendix. There we note that the urban-rural wage differential corresponding to any level of unemployment may depend on a number of other variables, e.g., the rate of growth of urban employment.

8. See Appendix, p. 226.

9. If, for instance, $\phi^{\prime}$ is constant, so that

$$
\frac{w_{u}}{w_{r}}=\frac{k}{1-U}
$$

then (11a) and (11b) both assert that $k \geqslant 1$. 
Elsewhere, ${ }^{1}$ we have argued that the relevant rural wage at least in the East African context - for purposes of migration (labor turnover) is the value of the marginal productivity of labor.

The production function in the rural sector is described by

$$
Q_{r}=G\left(K_{r}, L_{r}, A\right) \text {, }
$$

where $A$ stands for arable land. Again, for short-run analysis, we shall assume that $K_{r}$ and $A$ are fixed.

There has been some controversy over whether an "open"-economy or "closed"-economy model is more appropriate to various developing countries. There seems to be some consensus that at least for most smaller African countries, the open economy model is more appropriate, and hence in the subsequent analysis we shall pursue its implications. However, the analysis may easily be modified for the closed-economy situation.

This assumption enables us to choose our units so that the price of output in both the rural and urban sectors is (constant at) unity. Then we write

$$
w_{r}=G_{L_{r}} \text {. }
$$

\section{The Market Equilibrium}

The equilibrium of the economy is described by the wage determination equations for the urban and rural sectors, the labor allocation-migration equation, and the equilibrium condition,

$$
L_{r}+N_{u}=L_{r}+\frac{L_{u}}{1-U}=L,
$$

where $L$ is the total labor force and $N_{u}$ is the number of workers

1. J. E. Stiglitz, "Rural-Urban Migration, Surplus Labor, and the Relationship between Urban and Rural Wages," East Africa Economic Review (Dec. 1969), 1-27. I argued there that the allocation of labor between the sectors depends on, among other things, the pattern of land ownership (whether owned privately or communally) and arrangements for "sharing" among members of a community. In the African context, probably the most reasonable assumptions yielded the result that labor allocated itself so that the marginal productivity of labor in the rural sector equaled the expected urban wage (ignoring risk aversion and transportation costs). Since the common pattern in Africa is that some members of the family remain in the rural sector working the land, and some migrate temporarily to the urban sector; in deciding whether to migrate, the worker needs only to compare his marginal product in the rural sector with his expected income in the urban sector. Other circumstances were delineated where labor allocated itself so that the average productivity of labor in the rural sector equaled the expected urban wage. (In particular, this required the absence of a landless rural laboring class receiving as a wage its marginal product, and communal ownership of land, with the further stipulation that when individuals left the rural area, they no longer received any returns from the land. These assumptions are clearly not satisfied in most African economies.) For most of the analysis, it makes little difference whether we work with the marginal or average product hypothesis. 
(employed and unemployed) in the urban sector:

$$
N_{u}=\frac{L_{u}}{1-U} \text {. }
$$

To see the solution graphically, we rewrite the first-order condition (5), making use of the equilibrium condition (11)

$$
\begin{aligned}
w_{u} & =-T\left(q_{1}\left(1, \phi\left(\frac{1}{1-U}\right), U\right)\right. \\
& \left.+q_{2}\left(1, \phi\left(\frac{1}{1-U}\right), U\right)_{\phi}\left(\frac{1}{1-U}\right)\right)=h(U) .
\end{aligned}
$$

Under the hypothesis introduced above $((2 \mathrm{c})$ and $(2 \mathrm{~d}))$, it is easy to establish that ${ }^{2}$

$$
h^{\prime}(U)<0 \text {. }
$$

Then, from (11) we have

$$
w_{r}=\frac{w_{u}}{\phi(1 / 1-U)}=\frac{h(U)}{\phi(1 / 1-U)}
$$

and from (3)

$$
w^{*}=h(U)+T q(1, \phi(1 / 1-U), U)=w^{*}(U)
$$

(20a) $\frac{d w^{*}}{d U}<0$.

The rural wage and total unit labor costs in the urban sector may both be simply written as functions of $U$. For each value of $U$ then we can calculate the demand for labor, using (10). Since labor costs move inversely with respect to $U$, as $U$ increases, demand for labor in the rural sector increases, urban employment increases, and urban unemployment increases. Equilibrium is the point where (15) is satisfied. See Figure V.

Figure V may be used to give us some quick comparative static results: (a) An increase in the growth of urban employment, which results in a lower value of $w_{u} / w_{r}$ corresponding to any given $U$ (or any other change having the same effect on $\phi$ ), raises the unemployment rate. ${ }^{3}$ (See Figure VIa.) (b) A labor-augmenting invention in

2. For most of the ensuing analysis, it is the restriction embodied in (18) and not the restrictions embodied in $(7)$ or $(2 \mathrm{~b}-2 \mathrm{~d})$ that is crucial. The relationship between the two can easily be seen by taking the derivative of (17) with respect to $U$ and comparing the resulting expression with (2b) and (2d). Then

3. Let $\phi[(1 / 1-U), a]=w_{u} / w_{r}$, where $a$ is a shift parameter. Let $\phi_{a}<0$.

$$
\left(\frac{\partial w_{u}}{\partial a}\right)_{v=\text { constant }}=-T\left(q_{12}+q_{22} \phi+q_{2}\right) \phi_{a}>0,
$$

using (2c). Similarly,

$$
\begin{aligned}
& \left(\frac{\partial w^{*}}{\partial a}\right)_{V=\text { constant }}=-T\left(q_{12}+q_{22} \phi\right) \phi_{a}>0 ; \\
& \left(\frac{\partial w_{r}}{\partial a}\right)_{V=\text { constant }}=\frac{1}{\phi}\left(\frac{\partial w_{u}}{\partial a}\right)_{V=\text { constant }}-\frac{h}{\phi^{2}} \phi_{a}>0 .
\end{aligned}
$$




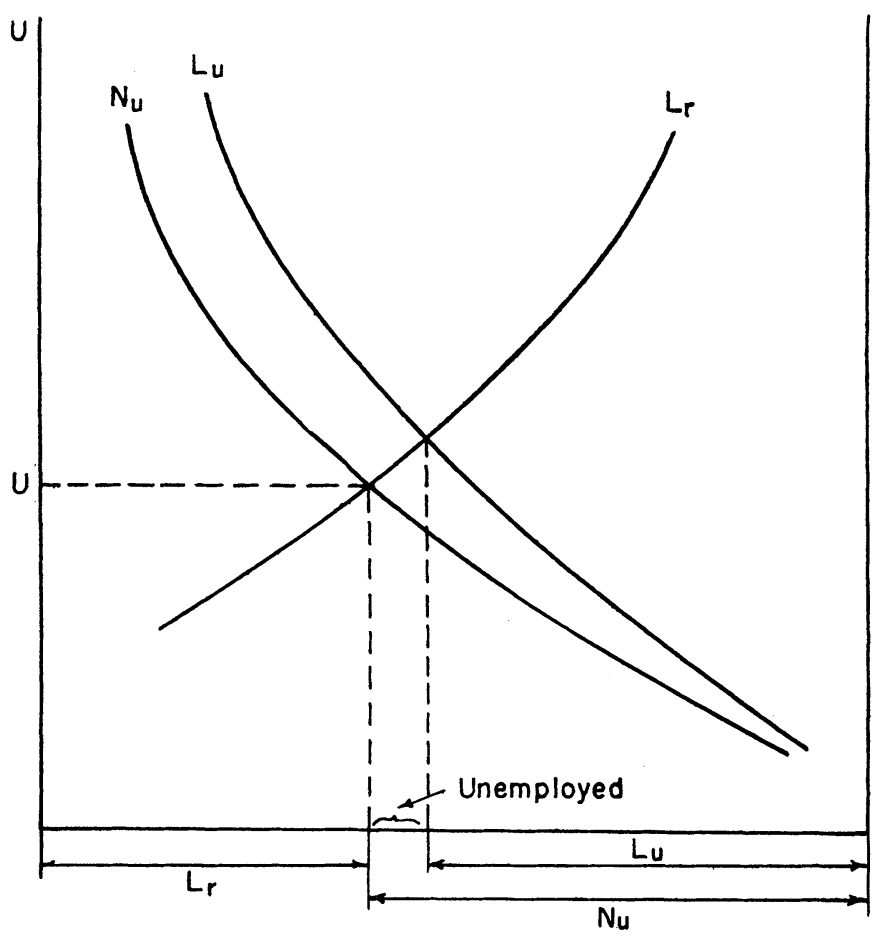

Figure V

Market Equilibrium

the rural sector lowers the unemployment rate and the level of urban employment. (See Figure VIb.) ${ }^{4}$ (c) A labor-augmenting invention in the urban sector lowers ${ }^{5}$ the unemployment rate and the level of rural employment (raises the rural wage). (See Figure VIc.) (d) The effects of an increase in the capital stock in the rural and urban sector are the same as those discussed in (b) and (c).

\section{Optimal Allocation of Labor and Determination of Urban Wage LeVel}

The preceding section provided an endogenous theory of the determination of an equilibrium level of unemployment and wage differential between the urban and rural sectors. How does this equilibrium compare with the one that would be generated by a gov-

4. Provided it is not "Pigou labor saving," i.e., provided the elasticity of substitution is sufficiently great.

5. Under the same conditions given above in note 4, p. 000 . 
Figure VIa

Comparative Statics: Effects of Downward shift in $\phi$

\section{Figure VIb}

Comparative Statics: Effects of Labor-Augmenting Invention in Rural Sector

Figure VIc

Comparative Statics: Effects of Labor-Augmenting Invention in Urban Sector
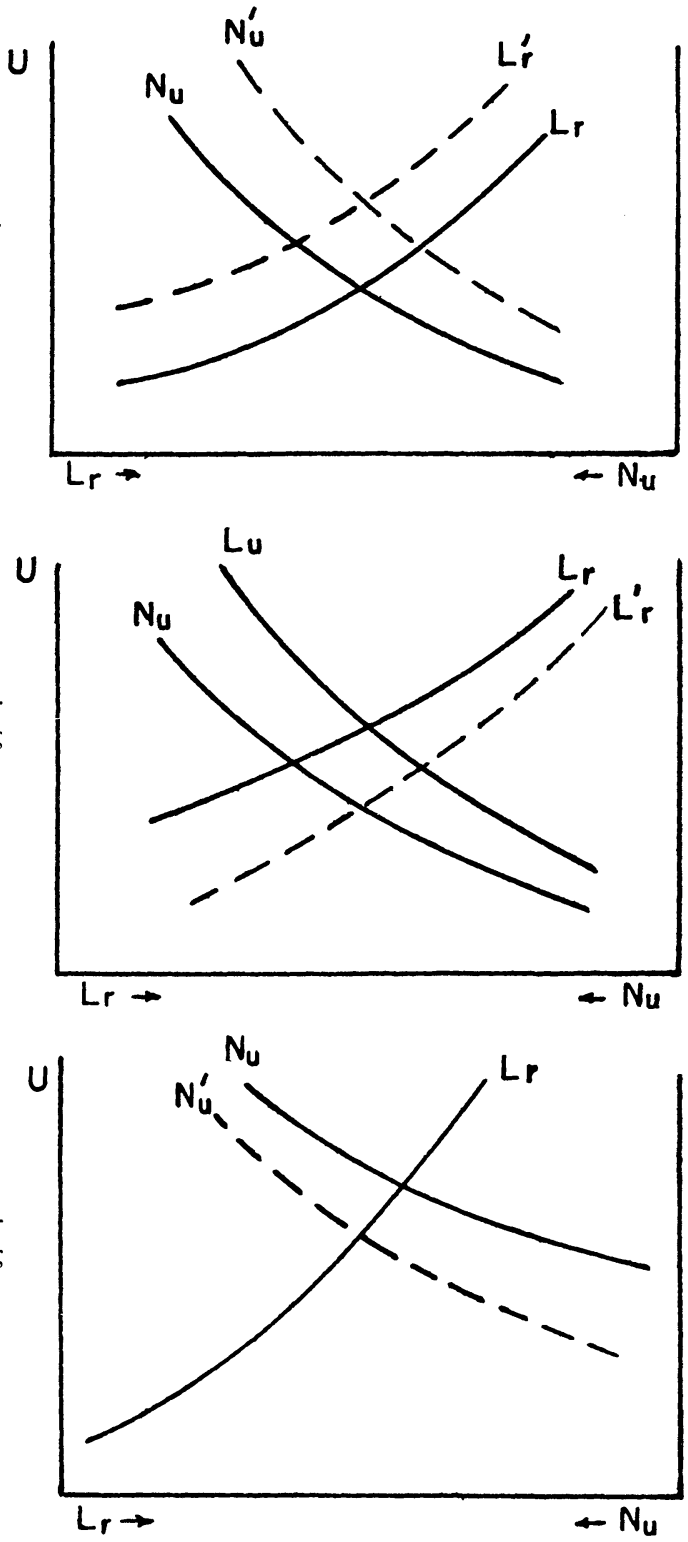

ernment attempting to maximize the value of national output but that cannot control migration directly?

The government's objective then is to maximize net national output

$$
Q_{u}+Q_{r}-T L_{u} q
$$


subject to the labor allocation constraint (15) and the free migration equilibrium condition (11). Assume that the government directly controls the urban sector (but not the rural sector). Then it can "choose" $L_{u}$ and $w_{u}$. But rather than maximize (21) subject to the constraints (11) and (15) with respect to these variables, let us assume that the government controlled directly $L_{u}$ and $U$, the unemployment rate. By solving this problem, there will emerge an equilibrium $w_{u}$, which, if the government set the wage at that level, would generate the indicated level of unemployment.

Hence our problem may be reformulated (assuming $K_{u}, K_{r}$, and $A$ are fixed):

$$
\begin{aligned}
& \max _{\left\{U, L_{\mathrm{u}}\right\}} G\left(L-\frac{L_{u}}{1-U}, K_{r}, A\right)+F\left(L_{u}, K_{u}\right) \\
& -T q\left(1, \phi\left(\frac{1}{1-U}\right), U\right) L_{u},
\end{aligned}
$$

which yields the first-order conditions (after some simplification),

$$
\begin{aligned}
& \frac{w_{r}}{(1-U)^{2}}+T\left(\frac{q_{2} \phi^{\prime}}{(1-U)^{2}}+q_{s}\right)=0 \\
& \frac{w_{u}}{(1-U)_{\phi}} \doteq F_{L}-T q .
\end{aligned}
$$

Equations (23), (24), and (15) describe the general equilibrium of the economy with the government-controlled urban sector. We wish to compare this equilibrium with that for the market economy described by (4), (9), and (15).

a. The "shadow price of labor" in the urban sector is equal to

$$
\frac{1}{\phi\left(\frac{1}{1-U}\right)(1-U)}
$$

times the urban wage. (See (24).) Thus, in the case of (13) (where the expected urban wage is equal to $w_{u}(1-U)$, and migration continues until the expected urban wage is equal to the rural wage), the shadow price of labor is just the urban wage, even though there is unemployment. The reason for this is that at a fixed wage if the unemployment rate is say 5 percent, when 100 additional workers are hired for the urban sector, 105 workers leave the rural sector. The opportunity cost of labor is less than the urban wage, but the induced unemployment just offsets this. Normally, $\phi(1 / 1-U)$. $(1-U)$ is slightly greater than one, so that the induced unemployment for hiring one worker in the urban sector is smaller. For instance, if the unemployment rate is 20 percent when the urban-rural 
wage ratio is 1.5 , then the shadow price of labor is $5 / 6$ the (optimally chosen) urban wage.

b. The market wage at any given level of unemployment may be greater or smaller than the optimum wage in the urban sector: ${ }^{6}$

$$
w_{u}^{c}(U) \gtrless w_{u}^{o}(U) \text { as } h^{c}(U) \gtrless h^{o}(U),
$$

where $h^{c}(U)$ is defined by (17) and

$$
h^{o}(U)=-T\left\{q_{2} \phi \phi^{\prime}+q_{3}(1-U)^{2} \phi\right\} .
$$

Competitive firms make three "mistakes" in calculating the effects of an increase in wages on labor turnover. First, they take the unemployment rate as given. But when all firms increase the wage rate, it increases the unemployment rate and hence lowers the turnover costs. Second, the competitive firms assume that $w_{r}$, the rural wage, is constant; hence, a given percentage increase in $w_{u}$ is equivalent to the same percentage increase in $w_{u} / w_{r}$. When all firms increase their wages, however, the rural wage does change. Moreover, we know that in equilibrium, increasing $w_{u} / w_{r}$ must be accompanied by increasing unemployment; hence, increasing unemployment has a secondary effect on turnover through increasing urban-rural wage differentials; this effect is larger, the larger is $\phi^{\prime}$. Third, each firm believes that it can get some competitive advantage relative to other firms in the urban sector in reducing labor turnover (due to movement of labor within the urban sector) by increasing its wage relative to them (i.e., $q_{1}$ was assumed to be negative). Obviously, when they all raise their wages together they obtain no competitive advantage over each other. Analytically, these three effects may be shown by rewriting (25):

$$
w_{u}^{o}(U) \gtrless w_{u}^{c}(U) \quad \text { as } \quad-\left(q_{3}(1-U)^{2} \phi+\phi q_{2}\left(\phi^{\prime}-1\right)\right) \gtrless-q_{1} .
$$

The two terms on the left-hand side of the inequality represent the first and second effects; the term on the right-hand side of the inequality is the intra-urban competition effect. The first two effects mean that firms underestimate the efficacy of increasing wages in reduced labor turnover ${ }^{7}$ the third effect means that they overestimate it. Normally, we would expect that the "intra-urban competition effect" is larger than the "unemployment" effect, so that firms are likely to pay too high wages. But it should be emphasized that it is possible that the competitive wage is too low. In the ensuing

6. Throughout the remainder of the paper we shall use superscript $c$ to refer to functions, values of variables, etc., in the competitive market solution, and a superscript $o$ for the optimal solution. Upon rewriting (23) using (11), we obtain $w^{o}{ }_{u}(U)=h^{\circ}{ }_{u}(U)$.

7. If (13) is true, $\phi^{\prime}=1$, and we are left with only the direct unemployment effect and the intra urban competition effect. 
analysis, we shall follow the conventional presumption in calling the case where $h^{c}(U)>h^{\circ}(U)$ the normal case.

c. In the normal case the equilibrium unemployment rate is higher in the market equilibrium than in the optimal allocation.

$$
U^{o} \gtrless U^{c} \text { as } h^{c}(U) \lessgtr h^{o}(U) .
$$

To see this, we first calculate total labor costs

$$
w^{*^{o}}=w_{u}+T q=h^{o}(U)+T q\left(1, \phi\left(\frac{1}{1-U}\right), U\right)=w^{*^{o}}(U)
$$

and

$$
w^{*^{o}}(U) \gtrless w^{* c}(U) \text { as } h^{o}(U) \gtrless h^{c}(U) \text { for any given } U .
$$

Turning to Figure VII, consider the case where $h^{o}(U)<h^{c}(U)$. We observe that, since the optimal solution involves a lower $w_{u}{ }^{*}$ at every $U$, it involves a higher $L_{u}$. Thus the $N_{u}$ curve shifts to the left. Since $w_{u}$ is lower at every $U, w_{r}$ is also lower, and $L_{r}$ greater, shifting the $L_{r}$ curve to the right. The net effect is to lower the unemployment rate.

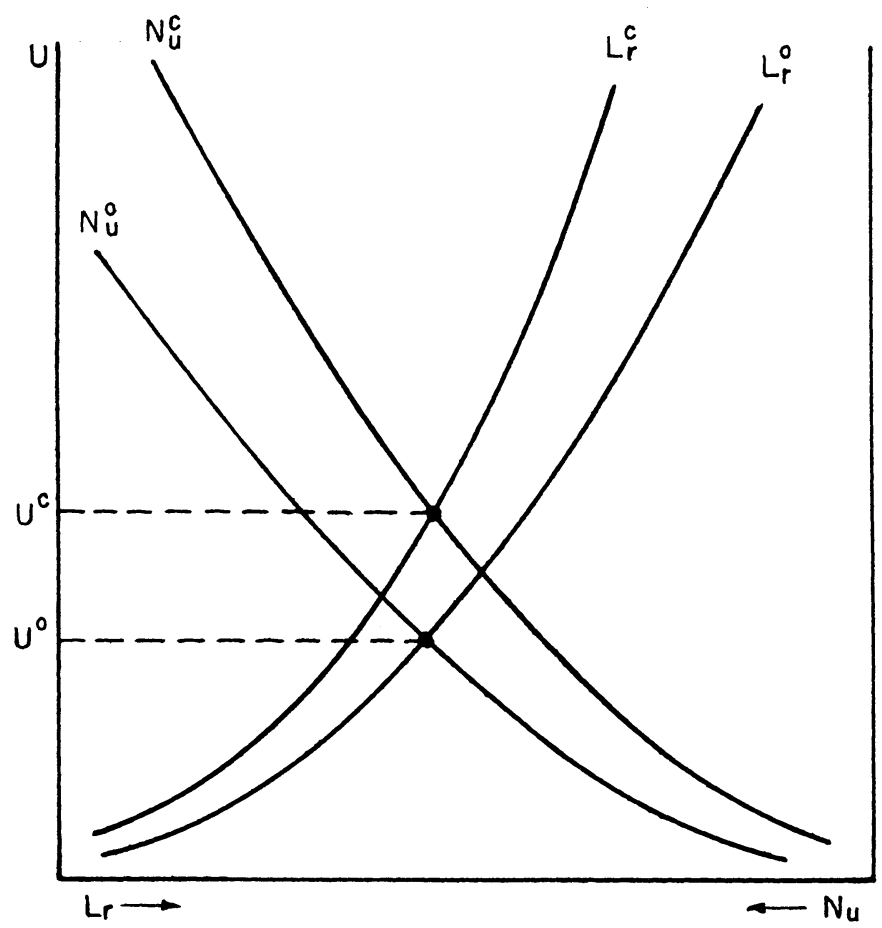

Figure VII

Comparison of "Optimum" and Market Equilibria 
d. In the normal case the equilibrium wage rate is higher in the market equilibrium than in the optimal allocation.

$$
w_{u}{ }^{o}=h^{o}\left(U^{o}\right) \lessgtr h^{c}\left(U^{c}\right)=w_{u}{ }^{c} \text { as } h^{o}(U) \lessgtr h^{c}(U) .
$$

There are two effects: at each unemployment level the market wage is higher, but from (27) the unemployment rate is higher in the market equilibrium. (Recall that the higher the unemployment rate, the lower the wage.) Equation (29) asserts that the first effect always dominates the second. ${ }^{8}$

e. In the normal case urban employment is lower in the competitive equilibrium than in the optimal allocation: ${ }^{9}$

$$
L_{u}{ }^{c} \lessgtr L_{u}{ }^{o} \quad \text { as } \quad h^{c}(U) \gtrless h^{o}(U) \text {. }
$$

f. Even in the normal case rural employment may be lower or greater in the competitive equilibrium than in the optimum. The ambiguity arises because although urban employment is lower, urban unemployment is higher. It is more likely that $L_{r}$ will increase if the elasticity of demand for labor in the urban sector is large, so that a given increase in the urban wage rate results in a large decrease in urban employment. ${ }^{1}$

8. We are considering the consequences to the equilibrium of a shift in the $h(U)$ function; let $h$ be a function of a shift parameter $a: h(U, a)$, where $h(U, a)=a h^{c}+(1-a) h^{o}$. Then equilibrium requires

$$
\begin{aligned}
& \frac{L_{u}\left(w_{u}^{*}(U, a)\right)}{1-C^{\prime}}+L_{r}\left(\frac{h(U, a)}{\phi\left(1 / 1-U^{\prime}\right)}\right)=L ; \\
& \frac{d U}{d a}=-\frac{\frac{L_{u}^{\prime}}{1-U} \frac{\partial w^{*} u_{u}}{\partial a}+\frac{L_{r}^{\prime}}{\phi} h_{a}}{\frac{L_{u}^{\prime}}{1-C^{\prime}} \frac{\partial w^{*}}{\partial U^{\prime}}+L_{r}^{\prime}\left(\frac{h_{U}}{\phi}-\frac{h}{\phi^{2}} \frac{\phi^{\prime}}{\left(1-C^{\prime}\right)^{2}}\right)+\frac{L_{u}}{(1-U)^{2}}} ; \\
& \frac{\partial w^{*}{ }_{u}}{\partial a}=h_{a} ; \\
& \frac{d w_{u}}{d a}=h_{a}+h_{v} \frac{d U}{d a} \sim h_{a}\left\{-L_{u}^{\prime} \frac{w_{u}{ }^{o}}{(1-U)_{\phi}}-L_{r}^{\prime} \frac{h \phi^{\prime}}{\phi^{2}}+L_{u}\right\}>0 .
\end{aligned}
$$

( denotes "is of the same sign as.")

9. Following the approach of the previous footnote,

$$
\begin{aligned}
\frac{d w^{*}{ }_{u}}{d a} & =\frac{\partial w^{*}{ }_{u}}{\partial a}+\frac{\partial w^{*}{ }_{u}}{\partial C^{\prime}} \frac{\partial C}{\partial a}=\frac{d w_{u}}{d a}-\frac{w_{u}{ }^{o}}{\phi\left(1-C^{2}\right)^{2}} \frac{d U}{d a} \\
& \sim\left[\frac{L_{r} \phi^{2}}{\phi^{2}}\left(w_{u}{ }^{o}-h \phi^{\prime}\right)+L_{u}\right] h_{a} .
\end{aligned}
$$

Since $w_{u}{ }^{\circ}<w_{u}{ }^{c}, \phi^{\prime} \geqslant 1$, this is positive.

1. $-\frac{d L_{r}}{d a}=\frac{1}{1-U} \frac{d L_{u}}{d a}+\frac{L_{u}}{(1-U)^{2}} \frac{d U}{d a}$

If $\frac{w_{u}}{w_{r}}=\frac{k}{1-U}$, we have

$$
\sim h_{a} \frac{L_{u}}{w_{u}} \frac{L_{r^{\prime}}}{L_{r}} w_{r}\left[\frac{1}{\phi(1-U)} \frac{w_{u} L_{u}^{\prime}}{L_{u}}\left(\frac{w_{u}{ }^{0}}{h}-\phi^{\prime}\right)-1\right]
$$

$$
\frac{-d L_{r}}{d a} \sim\left(-\frac{w_{u} L_{u}^{\prime}}{L_{u}}\right)\left(\frac{w_{u}^{o}}{w_{u} k}-1\right)+1 .
$$


An alternative way of seeing the difference between the optimal and competitive wage policies is an extension of the "monopolistic competition" diagram used earlier.

In Figure VIII we have drawn the training cost curve $q T$ as a function of $w_{u}$, for given $w_{r}$. The slope of the curve perceived by the firm differs from the actual slope for the reasons discussed earlier.

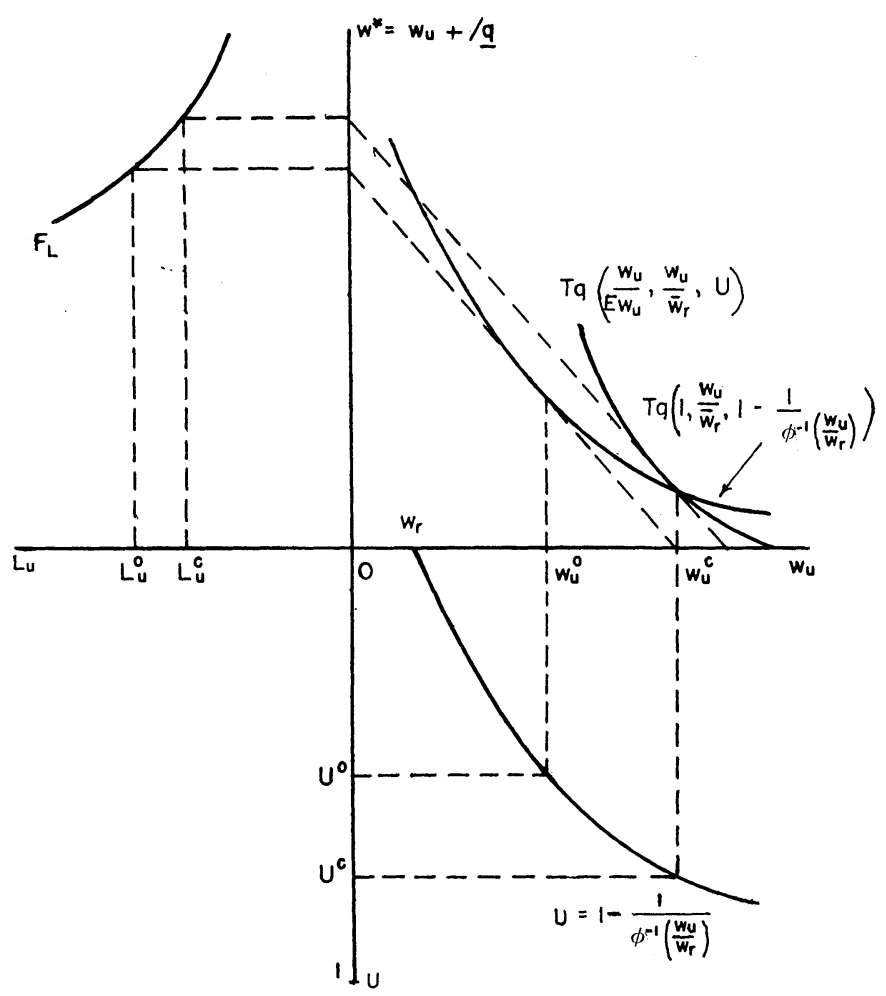

Figure VIII

Comparison of "Optimum" and Market Equilibria

If $h^{c}(U)=h^{\circ}(U)$, the wage would be optimal. If, as we would expect, $h^{c}(U)>h^{\circ}(U)$, the competitive wage is above the optimal level, resulting in a higher level of unemployment, less employment in the urban sector, and a lower rate of turnover than is optimal.

In Figure VIII we have also compared the competitive and optimum equilibria. $^{2}$

Normally, we would expect $1-w_{u}{ }^{o} / w_{u} k$ to be small, so $d L_{r} / d a<0$, but if, say, $w_{u}{ }^{0}=\frac{1}{2} w_{u}$ and $k=2$, then $d L_{r} / d a>0$ if $-w_{u} L_{u}^{\prime} / L_{u}<3 / 4$. $w_{r}$.

2. Figure VIII may easily be modified to take into account changes in 


\section{WAge Subsidies}

The government can induce competitive firms to behave optimally by imposing a hiring subsidy (paid for by, say, a profits tax) at a rate

$$
T\left(1-\frac{\left(q_{2} \phi^{\prime}+q_{3}(1-U)^{2}\right) \phi}{q_{2}+q_{1}}\right),
$$

where the variables are evaluated at the optimum (24). There are, of course, obvious practical difficulties to giving a hiring subsidy, particularly in African economies. An individual may have, for instance, several names, and he could be "hired" and "fired" successively by the same firm.

It is perhaps because of these practical difficulties that most economists have advocated a wage subsidy rather than a hiring subsidy.

In discussing the consequences of a wage subsidy, we must specify (i) how the revenue for the wage subsidy is raised and (ii) what are the general equilibrium consequences both in the long run and in the short run of the wage subsidy-cum-tax system. It is in this respect that previous analyses recommending wage subsidy schemes have failed.

More specifically, previous arguments for wage subsidies have been less than convincing for the two reasons already noted in the introduction. First, they have failed to take into account the migration that would be induced into the urban sector as a result of the increased employment in the urban sector; this leads to increased unemployment (even at a fixed unemployment rate). Second, they have implicitly assumed that there is a fixed real wage that will be unaffected by the wage subsidy, i.e., there is no "shifting" of the wage subsidy to the employee. In our endogenous model of wage determination, we can always show that a wage subsidy leads to increased urban wages, and hence, not only does the number of unemployed individuals increase, but the unemployment rate in the urban sector actually increases as a result of the wage subsidy.

As a result of these two effects, a wage subsidy may actually reduce GNP. Indeed, a wage tax is indicated.

In the discussion below, we shall assume that the tax revenue for the wage subsidy comes from a profits tax, which is not shifted at all. Thus, the only consequences we need inquire into are those relating directly to the wage subsidy.

To see how a wage subsidy, say at the rate $(1-\tau)$, changes be- 
havior, we observe that the first-order condition (4) is now

$$
1-\tau+T\left(\frac{q_{1}}{w_{u}}+\frac{q_{2}}{w_{r}}\right)=0 .
$$

Or multiplying through by $w_{u} /(1-\tau)$, we obtain

$$
w_{u}=-\frac{T}{1-\tau}\left(q_{1}+q_{2} \frac{w_{u}}{w_{r}}\right)=\frac{h^{c}(U)}{1-\tau} .
$$

Similarly,

$$
\begin{aligned}
w_{r} & =w_{u} / \phi(1 / 1-U)=\frac{h^{c}(U)}{\phi(1 / 1-u)(1-\tau)} \\
w^{*} & =w_{u}(1-\tau)+T q\left(1, \phi\left(\frac{1}{1-U}\right), U\right) \\
& =h^{c}(U)+T q\left(1, \phi\left(\frac{1}{1-U}\right), U\right)=w^{*}(U),
\end{aligned}
$$

where, as before, $h^{c^{\prime}}<0, d w_{r} / d U<0, w_{u}{ }^{* \prime}<0$.

Turning to Figure IX, we observe that changing $\tau$ does not

u

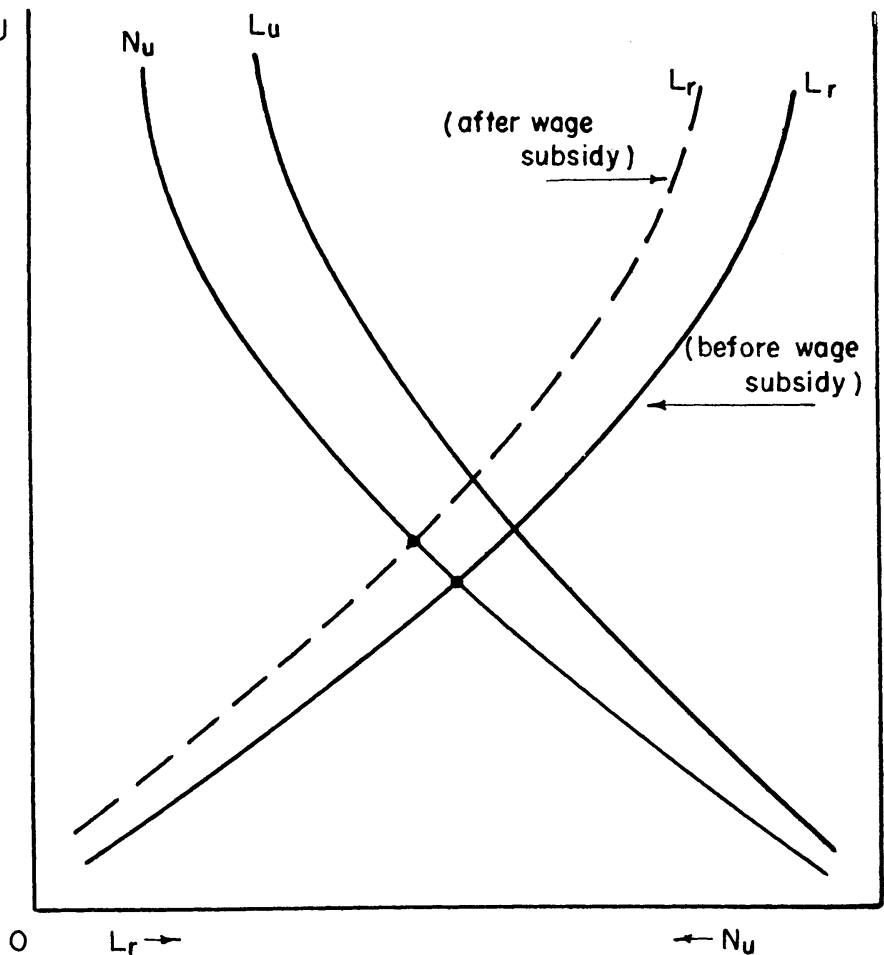

Figure IX

Effects of a Wage Subsidy 
affect the urban labor curves at all; but for each value of $U, w_{r}$ increases when $\tau$ increases, and hence the demand for labor decreases. This results in a higher unemployment rate, a higher urban wage ${ }^{3}$ and more urban unemployment. Moreover, wage costs - both direct ${ }^{4}$ and training costs - in the urban sector have decreased, so urban employment has also increased.

Thus, a wage subsidy does accomplish what its advocates claim - a higher employment rate - but it is accompanied by some deleterious side effects. In fact, these side effects are so strong that they imply that it is not desirable to have a wage subsidy. If the expected urban wage is equal to the rural wage (so (13) obtains) at a fixed unemployment rate, the opportunity cost of hiring an extra urban worker is just his wage: for every extra urban worker hired, $1 /(1-U)$ workers leave the rural sector, and the foregone output, $G_{L} /(1-U)=w_{u}$, is just the nominal urban wage. But now there is the additional effect of an increase in the unemployment rate, which results in additional losses in output, although this is partially - but only partially - offset by the reduced hiring-training costs from the reduced turnover rates. Thus the wage subsidy reduces national output. ${ }^{5}$

National output may be written as

$$
G+F-T q L_{u} \text { : }
$$

The derivative of this with respect to $\tau$ is

$$
\left(\frac{-G_{L}}{1-U}+F_{L}-T q\right) \frac{d L_{u}}{d \tau}+\frac{\left(h^{o}(U)-h^{c}(U)\right)}{\phi(1-U)^{2}} L_{u} \frac{d U}{d \tau}<0,
$$

for $\tau>0$ if $\phi(1-U)-1$ is small.

Indeed, optimality requires that

$$
\begin{aligned}
\tau^{*} & =\frac{U\left\{h^{c}(U)-h^{o}(U)\right\}}{(1-U) h^{c}(U) \eta_{u^{d}}{ }^{d} \frac{\partial \ln w^{*}}{\partial \ln U} \phi(1-U)} \\
& -\left(\frac{1}{\phi(1-U)}-1\right),
\end{aligned}
$$

where $\eta_{u}{ }^{d}=d \ln L_{u} / d \ln w^{*}$. If $\tau^{*}<0$, a wage tax, not a wage subsidy, is called for. ${ }^{6}$

3. Since $w_{r}$ is higher and $U$ is higher, $w_{u}=w_{r} \phi(1 / 1-U)$ must be higher.

4. $w_{u}(1-\tau)=h^{c}(U)$.

5. Note that although there is this trade-off between urban employment and national output, there is no trade-off between total employment and output.

6. Implicit in the above analysis is the assumption that training costs are fixed in "output" terms rather than in "labor" terms. However, the qualitative results of this paper do not depend on that assumption. Consider, for 
Long-Run Consequences of Wage Subsidies Financed by Profits Tax

So far, we have analyzed the short-run consequences of the wage subsidy. The major long-run consequences with which we need be concerned are those arising from the effects on savings. ${ }^{7}$ If a larger proportion of profits are saved than of wages, the profits taxwage subsidy will decrease savings on two accounts: First, we have noted that the average wage $\left(w_{r}=w_{u}^{e}\right)$ has increased, so that total wage payments have increased. But we have also noted that output has decreased. Labor receives a larger proportion of a smaller "pie," and profits are unambiguously reduced. Thus, even if savings did not depend on the distribution of income, it would be reduced, a

\section{instance, the more general case where} $w^{*}{ }_{u}=w_{u}+\left(w_{u} \lambda+(1-\lambda)\right) T q$

where for simplicity, we assume $\lambda$ constant. With a wage subsidy, this becomes $w^{*}=w_{u}(1-\tau)+\left(w_{u} \lambda(1-\tau)+(1-\lambda)\right) T q$.

$w_{u}$ is chosen so that

or

$$
(1-\tau)\left[1+\lambda T q+w_{u} \lambda T \frac{d q}{d w_{u}}\right]+(1-\lambda) T \frac{d q}{d w_{u}}=0,
$$

$$
\begin{aligned}
& (1-\tau)[1+\lambda(T q-h(U))]-(1-\lambda) \frac{h(U)}{w_{u}}=0 \\
& w_{u}=\frac{(1-\lambda) h}{(1-\tau)[1+\lambda(T q-h)]}, \lambda<1 \\
& w^{*}{ }_{u}=\frac{(1-\lambda) h(1+\lambda T q)}{1+\lambda(T q-h)}+(1-\lambda) T q=w^{*}(U),
\end{aligned}
$$

so the analysis is unaffected, provided that $\lambda<1$. In the polar case of $\lambda=1$, we obtain

$$
\frac{d w^{*}{ }_{u}}{d w_{u}}=(1-\tau)(1+T q-h(U)),
$$

which is solely a function of $U$. Hence in equilibrium

$$
h\left(U^{*}\right)=1+T q\left(1, \phi\left(1 / 1-U^{*}\right), U^{*}\right) \text {. }
$$

To find $w_{u}$, we solve the equations

$$
\begin{aligned}
& w_{r}=w_{u} / \phi\left(1 / 1-U^{*}\right) \\
& w_{r}=G_{L}\left(L_{r}\right)
\end{aligned}
$$$$
w^{*}{ }_{u}=(1-\tau) w_{u}\left(1+T q\left(1, \phi\left(1 / 1-U^{*}\right), U^{*}\right)\right)=F_{L} \text {. }
$$

In this polar case, a wage subsidy does not change $U$; it increases rural and urban wages, decreases rural employment, increases urban employment and unemployment, and decreases national output (if $\phi(1-U)-1$ is small). $U=0.2$,

For reasonable values of the parameters, $\tau^{*}$ appears to be small. If

$$
\frac{h^{c}(U)-h^{o}(U)}{h^{c}(U)}=0.4
$$

(the competitive wage is 40 percent too high), $\eta_{u}{ }^{d}=2,-\frac{\partial \ln w^{*}{ }_{r}}{\partial \ln U}=0.2$ (a 1 percentage point increase in unemployment is associated with a 1 percent decline in total labor costs per worker), and $\phi(1-U)=1.2$, then $\tau^{*}=-4$ percent.

7. If the training costs were general rather than specific, there would be some advantages to increased employment in providing a more educated labor force. 
fortiori, when a larger percentage of profits are saved than wages. This decreased savings means in turn that the rate of creation of jobs in the future is also reduced.

\section{Other Sources of Finance for Wage Subsidy}

Other schemes for raising the revenue required for the wage subsidy besides a profits tax have also been suggested. One of the most widely discussed is a general sales tax. A general sales tax is, of course, simply equivalent to an income tax, i.e., a uniform tax on wages and profits. Such a tax clearly leaves the wage determination behavior in the urban sector unaffected, since it does not affect any of the relative wages (urban-rural or intra-urban). Thus, the shortrun consequences are identical to those described in the case of the profits tax; now, however, the distributional impact is somewhat lessened, and hence the reduction in savings is smaller. If only a tax on wage income is imposed, then the net effect of the wage subsidy-cum-wage income tax is to reduce labor income. Indeed, the reduction in labor income is greater than the reduction in national output, so that profits are increased:

$$
\frac{d\left\{F-\left[w_{u}(1-\tau)+T q\right] L_{u}\right\}}{d \tau}=-L_{u} \frac{d w^{*}{ }_{u}}{d \tau}>0 .
$$

All of these tax subsidy schemes have the same deleterious effects on output in the short run.

\section{Wage and Shadow Price of Labor in the Public Sector}

There are, of course, other policy instruments available to the government. First, even in mixed economies, a large part of the urban labor force is employed in the public sector. The government can decide on (a) the relative size of this public sector ${ }^{8}$ and the choice of technique (labor intensity) of the public sector; (b) the location of public sector activities, i.e., in the rural or urban sector; and (c) the wages paid in both locations.

Second, it can use other tax instruments to discourage urban unemployment - e.g., urban income taxes - or to encourage the use of more labor-intensive techniques - e.g., tariff reductions on selected machinery.

The first set of questions is pursued in this section. The urban income tax is discussed briefly in the next.

8. We assume, however, that the government is restrained from taking direct control of the "private sector"; if it can do that, we are in the situation described in section IV. 
In keeping within the framework of this paper, we assume that the capital stock in the government sector is given. ${ }^{9}$ Hence the production alternatives facing the public sector may be described by the (short-run) government production function,

$$
g^{g}\left(L_{u^{g}}, L_{r}^{g}\right),
$$

where $L_{u}{ }^{g}$ and $L_{r}{ }^{g}$ are government employees in the urban and rural sector. The government need not pay the same wage as the private sector, but may be constrained to pay the same wage in the urban and rural areas. The average wage in the urban sector is now

$$
W_{u}=\frac{w_{u} L_{u}+w_{u}{ }^{g} L_{u}{ }^{g}}{L_{u}+L_{u}{ }^{g}}
$$

and we replace (11) by ${ }^{1}$

$$
\frac{W_{u}}{w_{r}}=\phi\left(\frac{1}{1-U}\right) \text {. }
$$

The quit rate from the private sector should also now be a function of $w_{u} / w_{u} g$. But if the government had the same training costs as the private sector and acted as a private firm (ignoring, for instance, its effects on the unemployment rate), then it would pay the same wage; but since the government should take these effects into consideration (and assuming that training costs per employee are no greater in the urban government sector than in the private), $w_{u}^{g}<w_{u}$, and there will not be labor turnover from the private to public (urban) sector. On the other hand, turnover rates in the urban government sector will depend on the urban wage: ${ }^{2}$

$$
q_{u^{g}}=q_{u^{g}}\left(\frac{w_{u^{g}}}{w_{u}}, \frac{w_{u^{g}}}{w_{r}}, U\right) .
$$

The quit rate in the government rural sector will be assumed, for simplicity, to be fixed at $g_{r}{ }^{3}{ }^{3}$ the result of which is that the government sets $w_{r}{ }^{g}=w_{r}$.

9. If it were variable, it would simply give us two additional first-order conditions. The results on optimal labor allocation and wage setting in the government sector are not affected by this assumption.

1. This assumes in effect that it is the agricultural workers who migrate, since $w_{r} \leqslant w_{r}{ }^{0}$ (otherwise, the government cannot attract workers).

2. These functions are meant simply to be a convenient simplification capturing the "first-order effects" of a process that is clearly far more complicated; for instance, now that we have introduced a difference of wages in the urban sector, it is clearly possible for individuals to accept a government urban job and continue to seek employment in the private urban sector. This clearly has some effect on $w^{e}{ }^{e}$, which (35) does not probably capture properly.

3. We could let $q_{r}{ }^{0}$ be a function of relative wages as well; increasing $w_{r}{ }^{\circ}$ reduces labor turnover. If there is no government budgetary constraint, this is the only effect, so $w_{r}{ }^{0}$ is raised to the point where the quit rate is unaffected by further increases in $w_{r}{ }^{\circ}$. 
The government wishes to choose $L_{u}{ }^{g}, L_{r}{ }^{g}$, and $w_{u}{ }^{g}$ so as to maximize national output (subject, of course, to the free migration and total resource constraints). We can establish that, since there is no induced unemployment effect from hiring labor in the rural sector, the. shadow price of labor in the rural public sector is the rural wage. Since the government urban wage is below the private urban wage, hiring one more worker reduces the average urban wage and hence reduces the urban unemployment rate. This means that the shadow price on urban government workers is less than the average urban wage; on the other hand, it turns out, under fairly weak conditions, to be greater than the wage paid by the government in the urban sector. If the government pursues its optimal wage and hiring policy, there is still likely to be significant urban unemployment. ${ }^{4}$

\section{Urban INcome TAXes}

A proposal to get more directly at the problems arising from the urban-rural wage differential is to impose a tax on income in the urban sector only. The revenues from the tax may be used, for instance, to subsidize workers in the rural sector. Such a tax is always partially shifted, but the net result is always to decrease the unemployment rate. Again, the consequence of the decreased unemployment rate is to increase national output.

The wage determination equation in the urban sector is now derived from solving the problem

$$
\min \left\{w_{u}+T q\left(\frac{w_{u}}{E w_{u}}, \frac{w_{u} \lambda}{w_{r}}, U\right\}\right)
$$

where $\lambda<1$ for an urban income tax. Thus, we obtain as before

4. It can be shown that under fairly weak assumptions (e.g., an increase in the unemployment rate reduces turnover), optimality entails

$$
U>\frac{\frac{L_{u}}{L_{u}+L_{u}{ }^{g}} \eta_{u^{d}}\left(-\frac{\partial \ln w^{*}}{\partial \ln U}\right)}{1+\frac{L_{u}}{L_{u}+L_{u^{g}}{ }^{g}{ }^{d}}\left(-\frac{\partial \ln w^{*}}{\partial \ln U}\right)} .
$$

Assume, for instance, that $L_{u}=L_{u^{g}}, \eta_{u}{ }^{d}=2$ and that $\left(-\partial \ln w^{*} / \partial \ln U\right)=0.2$ (so, e.g., an increase in the unemployment rate from 20 to 21 percent would reduce labor costs by 1 percent). Then

$$
U>\frac{\frac{1}{2} 2 \frac{1}{5}}{1+\frac{1}{5}}=\frac{1}{6},
$$

i.e., there is still a fairly high unemployment rate. 


$$
\begin{aligned}
& w_{u}=h(U) \\
& w_{r}=\frac{\lambda h(U)}{\phi(1 / 1-U)} \\
& w^{*}{ }_{u}=w^{*}(U) .
\end{aligned}
$$

A decrease in $\lambda$ decreases the equilibrium unemployment rate, and hence increases $w_{u}$ - the tax is at least partially shifted - and $w^{*}{ }_{u}$. Hence urban employment actually decreases (See Figure X.)

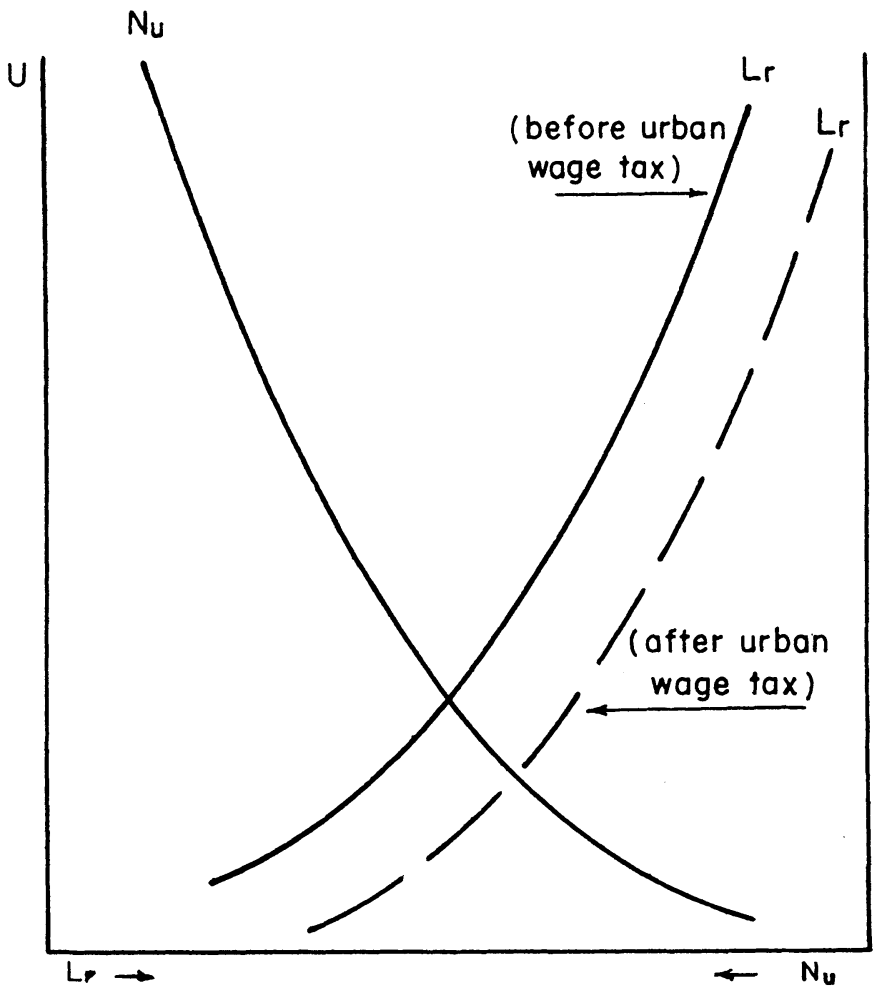

Figure $\mathrm{X}$

Effects of Urban Wage Tax

But, at least for small taxes, and for $\phi(1-U)$ near unity the gain from the reduction in the unemployment rate more than offsets the loss from the reduction in the output of the urban sector (provided $h^{c}(U)>h^{\circ}(U)$, as we would normally expect) : 


$$
\begin{aligned}
& \frac{d\left\{Q_{u}-T q L_{u}+Q_{r}\right\}}{d \lambda}=\left\{\left(F_{L}-T q-\frac{G_{L}}{1-U}\right) \frac{d L_{u}}{d w^{*}} \frac{d w^{*}}{d U}\right. \\
& \left.-\frac{G_{L} L_{u}}{(1-U)^{2}}-T\left(\frac{q_{2} \phi^{\prime}}{(1-U)^{2}}+q_{3}\right) L_{u}\right\} \frac{d U}{d \lambda} \\
& =\left\{w_{u}\left(1-\frac{\lambda}{\phi(1-U)}\right) \frac{d L_{u}}{d w^{*}} \frac{d w^{*}}{d U}\right. \\
& \left.+L_{u} T\left(\frac{\lambda q_{1}}{\phi(1-U)^{2}}-q_{3}+\frac{\left(1-\phi^{\prime}\right) q_{2}}{(1-U)^{2}}\right)\right\} \frac{d U}{d \lambda}<0,
\end{aligned}
$$

for $\lambda$, and $\phi(1-u)$ near unity. The required tax is relatively small: if $\phi(1-u)=1$ and $\Delta w / w$ is the percentage discrepancy between the urban market wage and the optimal wage,

then

$$
1-\lambda=\frac{\frac{\Delta w}{w}}{1+\frac{\partial \ln L_{u}}{\partial \ln w^{*}} \frac{\partial \ln w_{u}^{*}}{\partial \ln u}\left(\frac{1-u}{u}\right)}
$$

Hence if $\Delta w / w=25$ percent, $U=0.1, \partial \ln L_{u} / \partial \ln w^{*}=1.5$, $\partial \ln w^{*} / \partial \ln U=0.2$, then at 7 percent tax is indicated.

If $\phi(1-u)>1$, the required tax is even smaller. If $\phi(1-u)$ is sufficiently large, an urban wage subsidy rather than a wage tax is called for. ${ }^{5}$

\section{Concluding Comments and Summary}

This paper has provided a model in which the unemployment rate as well as the urban wage rate are endogenous variables. We would argue that the model explains at least part of the urban-rural wage differentials. Although we have focused on turnover costs as the "explanation" of why competitive firms are willing to pay more than is necessary simply to attract labor, other labor costs, such as absenteeism and work "effort," are likely to depend on very similar considerations. The formulation of the model has enabled us to determine clearly the effects of alternative policies on national output, urban employment, the urban unemployment rate, etc.

The results run counter to much of the development folklore.

a. Although the competitive wage is likely to be greater than the wage that the government would set if it controlled the urban

5. It should be emphasized that, although we have chosen what may be regarded as "reasonable" values of the parameter, these are only meant to be illustrative. 
sector directly (but could not directly control migration), the government will still set the wage at a level greater than the rural wage so there will be urban unemployment even with government controlling wages.

b. When the government controls directly the urban sector even though there is urban unemployment, the shadow price of labor may be equal to the urban wage.

c. A wage subsidy is not a good substitute for direct control of the urban sector. ${ }^{6}$ The wage subsidy is always partially shifted, and as a result, it always increases the unemployment rate and may reduce national output.

d. In a mixed economy, there is some presumption that the wage paid by the government in the urban sector will lie between the urban wage and the rural wage; the shadow price of labor in the rural sector is just the rural wage, but in the urban sector it is between the urban private sector wage and the urban public sector wage.

e. A tax on wage income in the urban sector is also always partially shifted, increases total labor costs, and decreases the unemployment rate. Usually, it also increases national output, but if $w_{u}(1-U) / w_{r}$ is large, just the opposite will occur.

\section{Appendix: "Nominal" and "Expected" Urban Wages and the UNEMPLOYMENT RATE}

The expected wage in the urban sector differs from the nominal wage because some part of the time that the individual is in the urban sector he will probably be unemployed. The length of time unemployed depends on the model of hiring hypothesized. The two simplest are ${ }^{7}$ (i) a random selection from. the unemployment pool, which leads to a Poisson distribution of the period of unemployment; (ii) a queue model, in which the individuals are hired in order of time of arrival in the urban sector.

Both are extreme cases of a more general model where the probability of being hired depends on the length of time in the unem-

6. Within the limited bounds of our analysis, we are ignoring the dynamic effects, the advantages of individual entrepreneurship, etc. All of this is to say that although in our model direct controls are better than indirect controls, I would hardly use this as a basis for arguing that the government should control the urban sector directly.

7. Harris and Todaro have considered still a different model in which individuals go to the hiring hall every day; the probability of being selected for work is just $1-U$, so the expected wage is $w_{u}(1-U)$. Remarkably enough, this is exactly the result yielded by the two models below when there is no growth. See J. E. Harris and M. Todaro, "Migration, Unemployment and Development: A Two-Sector Analysis," American Economic Review, LX (March $1970), 126-42$. 
ployment pool. Initially, it takes some time to make contacts with potential employers and with individuals who can make contacts with employers. The longer one is in the city, the more extensive the network of contacts is, and hence the greater the probability of being hired (in any interval of time). On the other hand, employers may feel hesitant to hire someone who has been unemployed for an extensive period of time. He may have lost the requisite "work habits," and there may be some reason that other employers have turned this individual down that the employer in question may not know about. This leads eventually to a decrease in the probability of being hired in any given interval of time. (See Figure XI.)

In any case the expected wage is then a function of the nominal wage in the urban sector, the expected duration of unemployment, and the total anticipated time on the job (in the urban sector):

$$
w_{u}^{e}=\frac{w_{u} D}{D+t_{u}}=\frac{w_{u}}{1+t_{u} q}
$$

where $D$ is the expected duration on the job $(=1 / q)$ and $t_{u}$ is the expected duration of unemployment. ((A.1.) implicitly assumes a zero discount rate. More generally, we have, if $r$, the rate of interest, is positive

$$
w_{u}^{e}=w_{u} \frac{e^{-r t_{u}}\left(1-e^{-r D}\right)}{1-e^{-r\left(D+t_{u}\right)}}
$$

which reduces to (A.1) when $r=0$ (using L' Hôpital's Rule). Using (A.1.') complicates the analysis but does not change the qualitative results. Hence we continue our discussion using (A.1).)

To see what $q t_{u}$ depends on, consider first the "Poisson model"; the probability of being hired in any period is equal to the number of "hires" divided by the number of job seekers; the number of hires is equal to the number of new jobs being created $g_{u} L_{u}$, where $g_{u}$ is the rate of growth of jobs, plus the number of replacements arising from quits $q L_{u} .^{8}$

The number of job seekers is equal to the number unemployed. Let $N_{u}$ be the total urban labor force, so

$$
\frac{L_{u}}{N_{u}}=1-U,
$$

and the remainder unemployed is solely $U N_{u}$. Thus, the probability of being hired in any small interval $d t$ is

$$
\frac{L_{u}\left(g_{u}+q\right)}{U N_{u}} d t=\frac{\left(g_{u}+q\right)(1-U) d t}{U}
$$

8. It may have been noted that here as in (A.1) we use the same symbols for "duration in the urban sector" as we used earlier for "duration on the job." Although this makes sense in the context of our simplified model, since in the equilibrium all firms are identical and pay the same wage, so there is in equilibrium no intrafirm movement of labor in the urban sector, it should be emphasized that this is not an essential assumption in the analysis. We could have written (A.1) replacing $q$ with $q^{*}$ where $q^{*}$ is the rate of leaving the urban sector, and the expression we derive below (A.4) would be unaffected. 
from which it immediately follows that

$$
\text { (A.3) } \quad t_{u}=\frac{U}{(1-U)\left(g_{u}+q\right)} \text {. }
$$

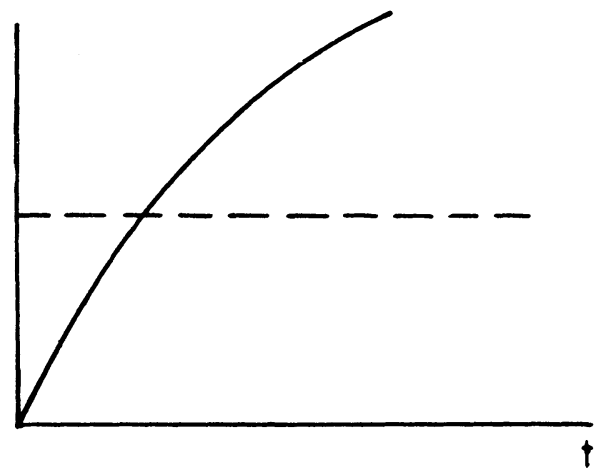

Figure XIa

\section{Poisson Model}

Figure XIb

Queue Model

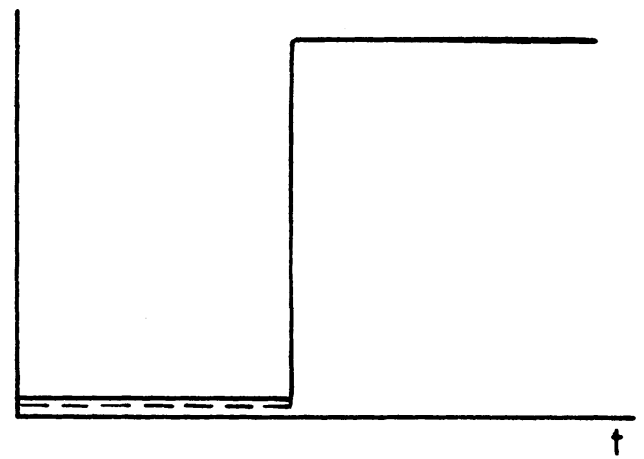

Figure XIc

More General Model

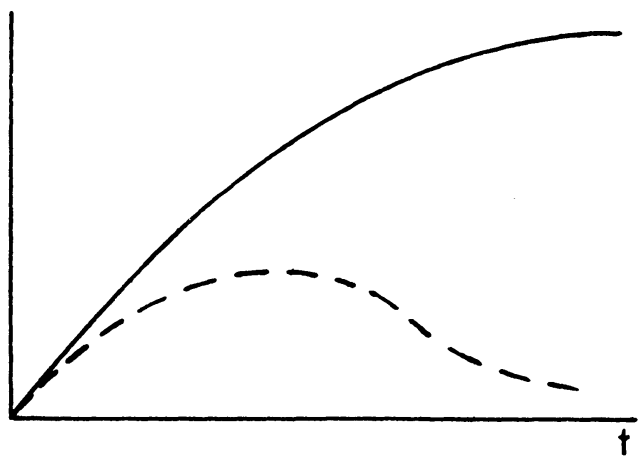

Alternative Hiring Patterns (The broken line is the probability of being hired in any interval of time. The solid line is the percentage of individuals arriving in urban sector employed by time $t$.) 
Substituting into (A.1), we obtain

$$
w_{u}^{e}=\frac{w_{u}^{e}(1-U)}{1-\frac{g_{u} U}{q+g_{u}}}
$$

(A.4') $w_{u}^{e}=w_{u}(1-U)$ when $g_{u}=0$.

Alternatively, if we consider the queue model, we obtain almost identical expressions. The flow of individuals into the urban sector equals (in a static equilibrium) the flow out $q L_{u}$. The size of the unemployment pool is equal to the flow into it times the average duration of unemployment:

or

$$
q L_{u} t_{u}=U N_{u} \text {, }
$$

$$
t_{u}=\left(\frac{U}{1-U}\right) \frac{1}{q} \text {. }
$$

Again substituting into (A.1), we obtain (A.4').$^{9}$ For simplicity, in the subsequent analysis we shall let $g_{u}=0$. The analysis may easily be modified for the case $g_{u}>0$.

One objection may be made to (13): it probably predicts unemployment rates too large for the observed magnitudes of wage differentials. For instance, the ratio of real wages in the two sectors is often of the order of magnitude 1.5 to $2,{ }^{1}$ so that the unemployment rate should be (according to (13)) of the order of magnitude of 33 percent to 50 percent. The overestimate may be accounted for by several factors, some of which we have already noted: (a) risk aversion - the uncertainty of obtaining a job - undoubtedly deters a large number of individuals from coming to the urban centers and leads to the actual level of unemployment corresponding to any given urban-rural wage ratio being smaller than predicted by equation (13)..$^{2}$ (b) Similarly, lack of liquidity (imperfect capital markets) results in individuals being unable to stay in the urban centers for extended periods of time if they do not get a job. (c) We have implicitly assumed that the individual has to be in the urban centers in order to seek an urban job; in fact, individuals in the rural sector have contacts in the urban centers, and although their probability of getting an urban job is undoubtedly significantly enhanced by being in the urban center, it probably is still not worth their while

9. If the urban sector is growing at the rate $g_{u}$, we have

$$
\left(q+g_{u}\right) L_{u} \int_{0}^{t_{u}} e^{g_{u} t} d t=U N_{u}
$$

or

$$
\frac{q+g_{u}}{g_{u}}\left(e^{\left.g_{u} t_{u}-1\right)}=\frac{U}{1-U} .\right.
$$

When substituted into (A.1) this yields an expression slightly different from (A.4).

1. These probably exaggerate real wage differentials among unskilled laborers; relative prices differ markedly, so there is a serious index number problem. income.

2 . This is offset to some extent by the greater variability of agricultural 
to be away from the rural sector at peak demand times (harvest and planting) in the rural sector. (d) The exact form of (13) depends on one of the extreme hiring models (the queue or the Poisson model); other hiring patterns would yield different equations, although other models may actually lead to higher unemployment rates for given wage rate ratios (as, for example, if there is a growing labor force in the urban sector). (e) Transportation costs also discourage migration. (f) There may be relative nonpecuniary advantages of living in the rural districts, which also will discourage migration.

More generally, (11) may be derived by assuming that $t_{u}$ is a function of the unemployment rate and the quit (hiring) rate; then substituting (A.1) into (12), we obtain

$$
\frac{w_{u}}{w_{r}}=1+q\left(1, \frac{w_{u}}{w_{r}}, U\right) t_{u}\left(U, q\left(1, \frac{w_{u}}{w_{r}}, U\right)\right),
$$

which can be solved for $w_{u} / w_{r}$ as a function of $U$.

YALE UNIVERSITY 